Diabetes mellitus, periapikal enfeksiyon ve kök kanalı tedavisi ilişkisi

\section{The relationship between diabetes mellitus, periapical infection and root canal treatment}

\author{
Dr. Öğr. Üyesi Güher Barut \\ Yeditepe Üniversitesi, Diş Hekimliği Fakültesi, \\ Endodonti A. D., İstanbul \\ Orcid ID: 0000-0002-5990-5221
}

Öğr. Gör. Dr. Beliz Özel

Yeditepe Üniversitesi, Diş Hekimliği Fakültesi, Endodonti A.D., İstanbul

Orcid ID: 0000-0002-4917-6176

\section{Prof. Dr. Rabia Figen Kaptan}

Yeditepe Üniversitesi, Diş Hekimliği Fakültesi, Endodonti A.D., İstanbul

Orcid ID: 000-0003-0982-8050

Geliş tarihi: 12 Nisan 2020

Kabul tarihi: 14 Nisan 2020

doi: 10.5505/yeditepe.2020.55477

\section{Yazışma adresi:}

Güher Barut

Yeditepe Üniversitesi, Diş Hekimliği Fakültesi

Bağdat Cad. No:238 Kadıköy/İstanbul

Tel: +905398367226

E-posta: guherbarut85@hotmail.com
ÖZET

Diabetes mellitus (DM) en yaygın metabolik bozukluklardan biridir. DM, yara iyileşmesinde güçlükler, sistemik ve ağız içinde özellikle pulpa bütünlüğü üzerinde doğrudan etkisi görülen hiperglisemi ile karakterizedir. Yapılan çalışmalar kontrolsüz diyabet hastalarında kök kanal tedavisi intiyacının, periapikal lezyon yaygınlığının, kemik kayıplarının ve kök kanal tedavisi sonrası başarısızlığın daha yüksek olduğunu göstermektedir. Hiperglisemi, pulpa dokusunda bozulmuş kan dolaşımı ve iskemi sonucunda nekroz riskinin artmasına, buna ek olarak diş ağrısı ve hassasiyetlerin artmasına neden olmaktadır. Hipergliseminin kemik erimesini arttırıp, osteoblastik aktiviteyi azalttığı moleküler düzeyde açıklansa da DM ve kemik metabolizması arasındaki ilişki tam olarak anlaşılamamıştır. DM'nin sistemik etkilerinin yanı sıra ağız sağlığı ile ilişkisini bilmek, kök kanal tedavisinin teşhis, tedavi ve takibinde büyük önem taşımaktadır.

Anahtar kelimeler: Diabetes mellitus, kök kanal tedavisi, periapikal periodontitis

\section{SUMMARY}

Diabetes mellitus (DM) is a metabolic disorder that is seen frequently. DM is usually characterised with extended wound healing, systemic and oral conditions linked to hyperglisema that especially affects pulpal integrity. Recent studies have shown that patients not receiving treatment for diabetes show a higher incidence in root canal treatment, spread of periapical lesion, bone loss and low prognosis. Hyperglisemia causes an interrupted blood circulation in the pulpal tissue which leads to ischemia thus, an elevated risk for necrosis. Additionally, DM may increase dental pain and sensitivity. Although it is known that an increase in bone loss related to hyperglisemia was explained through a decrease in osteoblastic activity, the relationship between DM and bone metabolism is yet to be understood. A comprehensive knowledge of the systemical effect of DM along with its effects on oral health is essential for the diagnosis, treatment and follow-up in root canal treatment.

Keywords: Diabetes mellitus, periapical peridontitis, root canal treatment

GíRiş

Apikal periodontitis (AP), çoğunlukla kök kanal sisteminin mikrobiyal enfeksiyonundan kaynaklı olarak dişin kök ucu etrafındaki akut veya kronik iltihaplı durumdur. Diş kökünün etrafındaki lezyonlar, kök kanalı kaynaklı polimikrobiyal irritanlara karşı oluşan periapikal iltihapsal cevabı takiben meydana gelen AP'nin ardından oluşmaktadır., ${ }^{12}$ Avrupa'da AP görülme sıklığı \%61 olarak bildirilmiştir. ${ }^{3}$ AP varlığında, genellikle sadece endodontik tedavi bazı durumlarda ise cerrahi endodontik tedavi yapılarak periradiküler dokuların sağlığına kavuşması amaçlanmaktadır. $^{3}$

Periodontal hastalıklar (PH), AP'nin yanı sıra ağız içi inflamasyona sebep olan enfeksiyon odaklarından bir diğeridir. Bu iki odağın sistemik hastalıklar ile ilişkili olduğu tıp ve diş hekimle- 
ri gözden kaçırmamalıdır. ${ }^{4}$

Son yıllarda yapılan pek çok epidemiyolojik çalışmada sistemik hastalıklar ile $\mathrm{PH}$ ilişkisi incelenmiştir. Bu araştırmaların sonucunda, $\mathrm{PH}^{\prime} ı$ n diabetis mellitus (DM), ${ }^{5,6}$ koroner kalp hastalığı $(\mathrm{KKH})^{7}$ ve miyokard infarktüsü, ${ }^{8}$ düşük doğum ağırlığı, ${ }^{9}$ solunum hastalıkları ${ }^{10}$ ve menopoz sonrası kadınlarda osteoporoz ${ }^{11}$ ile bağlantılı olduğu gösterilmiştir.

Endodontik tedavinin başarısızlığında kök kanallarındaki eğim, darlık, lateral veya aksesuar kanallar gibi lokal faktörlerin yanı sıra; bazı sistemik faktörlerin de etkisi olduğu bilinmektedir. ${ }^{12} \mathrm{PH}$ ile ilişkide olan sistemik hastalıkların AP ile de bağlantılı olduğu düşünülmektedir. ${ }^{13}$ Özellikle kemik yapımını bozan veya bağışıklık sistemini düşüren sistemik hastalıkların periapikal lezyon (PAL) oluşumu ve/ veya kök kanal tedavisi sonrasında periapikal dokuların iyileşmesiyle doğrudan ilişkide olabileceğini gösteren çaısşmalar bulunmaktadır. ${ }^{12-20}$ Literatüre bakıldığında AP ile $\mathrm{DM}, \mathrm{KKH}^{21,22}$ hipertansiyon ${ }^{23-25}$ ve sigara ${ }^{26}$ arasındaki ilişkiyi inceleyen pek çok çalışmaya rastlanmaktadır.

Bu derlemenin amacı, birçok araştırmaya konu olmuş ancak henüz tam olarak kesin bir karara varılamamış olan endodontik enfeksiyonlar ile DM arasındaki ilişkiyi değerlendirmektir.

\section{Diabetes Mellitus (DM)}

Diabetes mellitus (Diabetes: Yunanca: idrara geçen, Latince: mellis = tatlı ya da bal), sıklıkla diabet ya da diyabet veya halk arasında şeker hastalığı olarak adlandırılan, genellikle kalıtımsal ve çevresel etkenlerin birleşimi ile oluşan ve kan glikoz seviyesinin aşırı derecede yükselmesiyle (hiperglisemi) sonuçlanan metabolik bir bozukluktur. ${ }^{27}$ Tüm DM hastalarının yaklaşık \%5-10 kadarı Tip 1 diyabettir. Tip 1 diyabette pankreastaki Langerhans adacıklarının ß hücrelerinin oto-immun, toksik veya viral sebeplerle kaybedilmesi sonucunda insülin üretimi azalmaktadır. Tip 2 diyabet ise tüm DM hastalarının \%85-90'ını oluşturmaktadır. Tip 2 diyabet; insülinin etkisine karşı direnç gelişmesiyle, insülin duyarlığının azalması sonucu insülin sentezi ve salgılanmasının azalması ya da bazen tamamen ortadan kalkması ile ortaya çıkmaktadır. ${ }^{28,29}$ Diyabetin kendisi ve diyabette kullanılan tedavi yöntemleri pek çok komplikasyonlara yol açabilir. Eğer hastalık iyi kontrol edilmezse hiperglisemi, ketoasidoz ya da nonketotik hiperozmolar koma gibi akut komplikasyonlar gelişebilir. Hastalığın uzun sürede ortaya çıkan kronik komplikasyolarının başlıcaları ise; dolaşım sistemi (kardiyovasküler) hastalıkları (hipertansiyon, kalp yetmezliği ve ateroskleroz gibi), kronik böbrek yetmezliği (nefropati), körlüğe sebep olabilen retina hasarı (retinopati), çeşitli tiplerde sinir hasarları (periferik nöropati) ve yara iyileşmesinin gecikmesine sebep olan mikrovasküler bozukluklar sayılabilmektedir. ${ }^{30}$

Diabetes Mellitus ile Pulpa ve Periodontal Doku Illişkisi DM'nin ağız ve diş eti hastalıklarının seyrinde değişime sebep olduğu kabul edilmektedir. ${ }^{31,32}$ DM hastalarında periodontitisin yaygınlığı, şiddeti ve ilerlemesinin arttığı gösterilmiştir. ${ }^{33,34}$ Mealey ve ark. ${ }^{35}$ diyabetik olmayan bireylerle kıyaslandığında diyabetik bireylerin periodontal hastalıklara yakalanma riskinin 3 kat fazla olduğunu rapor etmişlerdir. Bununla birlikte, DM ve PH arasında iki yönlü bir ilişkinin bulunduğu ve $\mathrm{PH}^{\prime}$ nin de $\mathrm{DM}$ hastalarının metabolik durumu üzerinde önemli bir etkisinin olduğu bildirilmektedir. ${ }^{36}$ Periodontitisin varlığı zamanla glisemik kontrolün kötüleşme riskini arttırmaktadır. ${ }^{37} \mathrm{PH}$ ' nin, sitokinler tarafından başlatılan genel sistemik bağışıklık tepkisinin aktivasyonunu arttırarak, obezite ile benzer şekilde insülin direncini başlatabileceği veya çoğaltabileceği ileri sürülmüştür. ${ }^{38}$ Kronik gram-negatif periodontal enfeksiyonlar, artmış bir kronik sistemik inflamatuar durumu in dükleyebilmekte veya devam ettirebilmektedir. Bu durum da artan insülin direncine ve zayıf glisemik kontrole sebep olmaktadır. ${ }^{37}$

$\mathrm{PH}$ ve AP arasında etken açısından benzerlikler bulunmaktadır. Bu nedenle, kronik periapikal enfeksiyon varlığının, DM'nin patogenezine katkıda bulunabileceği ve DM hastalarında glisemi kontrolünün kötüleşmesi için bir risk faktörü oluşturabileceği düşünülmektedir. ${ }^{4}$ Bender ve ark. ${ }^{39}$ DM hastalarında, periapikal enfeksiyon varlığının ve buna bağlı olarak gelişen lokal inflamasyonun artmasının, kan şekerinde de bir artışa neden olduğunu ve hastayı kontrol edilemeyen bir diyabetik duruma getirdiğini bildirmişlerdir. Bunun sonucunda insülin dozajında veya terapötik dozda bir artış gerektmektedir.

DM'nin pulpa bağ dokusu ve hücreleri üzerine etkisi incelendiğinde, doğrudan bir ilişkili bulunduğu ve zayıf glisemik kontrolün pulpa üzerinde olumsuz etkisinin olduğu görülmektedir. Hiperglisemi, pulpa dokusunda bozulmuş kan dolaşımı ve iskemi sonucunda pulpa nekrozu, diş ağrısı ve hassasiyet olma intimalinin artmasına neden olmaktadı $r^{40,41}$ (SSekil 1). ${ }^{42}$

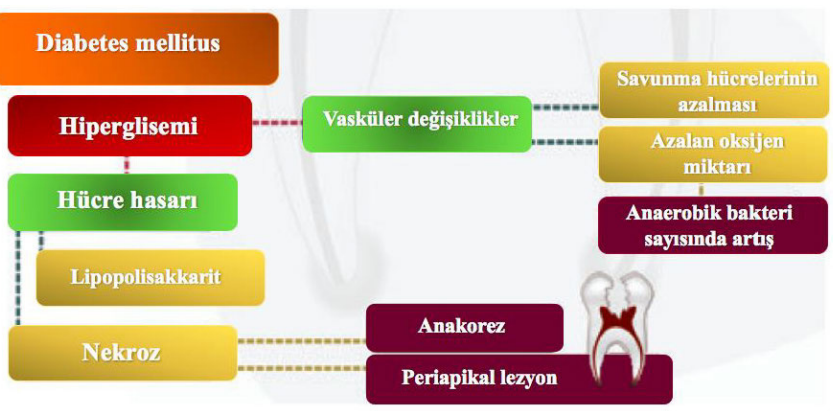

Şekil 1. Hipergliseminin pulpa üzerinde olumsuz etkisi (Lima ve ark.42)

DM hastalarında yeterli pulpa cevabının sağlanamadığı, mikroorganizmaların periapikal dokulara geçişi sonrasında AP gelișimi ve tedaviye cevabı üzerinde DM'un etkisi olduğunu gösteren pek çok çalışma yapılmıştır. ${ }^{43-46}$ Kök kanalı tedavisi yapılmamış dişlerde AP ve PAL bulgularının değerlendirildiği çalışmalara bakıldığında; Seguera-Egea ve ark.'nın ${ }^{43}$ Tip 2 DM hastaları ve sağlıklı bireyleri 
periapikal radyografi ve periapikal index (PAi) kullanarak periapikal durumu değerlendirdikleri çalışmalarında, DM hastalarında \%81 oranında bir veya daha fazla dişte AP varlığı tespit ederken sağlıklı bireylerde bu oranı \%58 olarak bulunmuşlardır. Diğer bir bulgu ise AP'li dişlerin yüzdesinin DM hastalarında (\%7) sağlıklı bireylerden (\%4) daha yüksek olduğudur. Marotta ve ark. ${ }^{44}$ da benzer şekilde DM hastalarında (\%15) AP'li dişlerin varlığına sağlıkI bireylerden (\%12) istatistiksel olarak anlamlı olmasa da daha sık rastlandığını göstermişlerdir. Bir diğer çalışmada Lopez-Lopez ve ark.45 kontrol altındaki Tip 2 DM hastalarının (50 birey; 20 erkek, 30 kadın) ve DM geçmişi bulunmayan sağlıklı bireylerin (50 birey; 22 erkek, 28 kadın) panoramik röntgenlerini değerlendirmişlerdir. Sonuçlara göre, Tip 2 DM hastalarında (\%74) bir veya daha fazla dişte AP görülme sıklığı sağlıklı bireylere göre (\%42) anlamIı derecede yüksek olduğu bulunmuştur. Ancak tüm bu çalışmalardan farklı olarak sağlıklı bireyler ile DM hastaları arasında kök kanalı tedavisi görmemiş dişlerde AP varlığı açısından bir fark olmadığı da Britto ve ark. ${ }^{46}$ tarafından gösterilmiştir.

PAL varlığında öncelikli tedavi seçeneği olarak kök kanal tedavisi uygulanmaktadır. Lopez-Lopez ve ark..$^{45} \mathrm{DM}$ hastalarının kök kanal tedavisi gereksinimlerini inceledikleri ve tip 2 DM hastası olan 50 bireyi değerlendirdikleri çaışmada; DM hastalarında bir veya daha fazla dişte kök kanal tedavisi varlığı oranı \%70 iken, sağlıklı bireylerde \%50 oranında daha düşük bulunmuştur. Bu çalışmanın sonuçlarından farklı olarak, Marotta ve ark. ${ }^{44}$ tip 2 DM hastalar ve sağlıklı bireyler arasında kök kanal tedavisi uygulanmış diş sayılarında anlamlı bir farklıık bulunmadığını göstermişlerdir. Değerlendirmeye dahil edilen birey sayısının sonuçlar arasındaki farklılıklara sebep olabileceği düşünülmektedir.

DM hastalarının kök kanal tedavisi esnasında savunma cevabının zayıf olmasından dolayı akut alevlenme (flare-up) riskinin sağlıklı bireylere göre daha fazla olduğu Fouad\&Burleson ${ }^{47}$ tarafından bildirilmiş olup, bu hastalarda kanal içi dezenfeksiyonun ve dekontaminasyonun özellikle önemli olduğu vurgulanmıştır. Akut alevlenme riskini azaltmak için kuronalden apikale uygulanan şekillendirme tekniklerinin kullanılması önerilmiştir. ${ }^{48,49}$ Ayrıca tamamen veya kısmen kontrolsüz DM'li hastalarda acil müdahale gereken durumlarda işlem sonrası enfeksiyon riskinin azaltılması ve geciken yara iyileşmelerini destekleyebilmek için antibiyotik kullanımının önerilebileceği bildirilmiştir. ${ }^{50,51}$ Kontrol alındaki DM hastalarda ise eşlik eden başka bir sistemik problem olmadığı sürece yapılacak tedavilerin yaklaşımında sağlıklı bireylerle benzer protokollerin uygulanmasında sakınca bulunmamaktadır. ${ }^{52}$ Sağlıklı bireylerde pulpa dokusu savunmada yetersiz kalıp pulpadaki mikroorganizmalar periapikal dokulara doğru ilerlemektedir. Enfeksiyöz sürecin gelişimine karşı savunma cevabı olarak periapikal lezyonun etrafı polimorfonükleer nötrofiller veya epitel tıkaçlar çevrilmektedir. Periapikal iltihap eksüdaları, mikroorganizmaları elimine etmek için (lökosit, makrofaj, lenfosit CD4+, CD8+ ve CD30+, plazma, natural killer, mast hücreleri) pek çok savunma kompanenti içerir. ${ }^{53,54}$ Bu eksüda kemiğin yeniden modellenmesinde ve periapikal iltihapsal cevabın gelişmesinde etkili olan pek çok sitokin barındırmaktadır. ${ }^{53}$ Tip 1 Thelper hücreleri (Th1) tarafından üretilen tümör nekroz faktör (TNF)-a, interferon (IFN)-c, interlökin (IL) -2 ve IL-12 gibi sitokinler kemik rezorpsiyon aktivatörleri iken; tip 2 Thelper (Th2) hücreleri tarafından üretilen IL-4, IL-5, IL-6, IL-10 ve IL-13 kemik rezorpsiyon inhibitörleridir.54,55 DM hastalarındaki yüksek glikoz seviyelerinin inflamasyona cevabında IL-4 azalmasına ve IL1b, IL-6, IL-8, IL10, TNFa'nın artmasına sebep olur. Hiperglisemi ile ilişkili olarak kemik iyileşmesi ve kemik turn-overındaki bozulma birçok çalışmada gösterilmiş ve yapılan histolojik çalışmalarda osteoblast sayısında azalma ve osteoklast sayısında artış oluştuğu izlenmiştir. ${ }^{56}$ Hiperglisemi, osteoblastik farklılaşmayı engellemekte, fosfor ve kalsiyum metabolizmasından sorumlu paratiroid hormonun yanıtını değiştirmektedir. Diyabetle ilişkili komplikasyonlardan biri olan diyabetik osteopeni, kemik mineral yoğunluğunun azalması, osteopöröz, kırık riskinde artış, kemik iyileşmesinde ve rejenerasyon potansiyelinde bozulma ile karakterizedir. ${ }^{57}$

Kök kanalı tedavileri tamamlandıktan sonra peripikal lezyon iyileşmesinin değerlendirildiği çalışmalara bakıldığında; Fouad\&Burleson'un ${ }^{47}$ bir çalışması kliniğe ışık tutacak niteliktedir. Araştırmacılar toplamda kök kanalı tedavisi tamamlanan 5494 bireyi (284 birey DM) ve kök kanal tedavisi sonrası iki yıl veya daha fazla takibi olan 540 bireyi (73 birey DM) çalışmaya dahil edip, kök kanalı tedavisi sonrasındaki PAL iyileşmelerini değerlendirmişlerdir. Uzun süre takip edilen 540 hastada kök kanal tedavisinin başarı oranının yüksek olduğu ancak PAL varlığında DM'nin başarı oranını düşürdüğü gözlenmiş̧ir.

Dominguez ve ark. ${ }^{58}$ DM hastası 83 bireyi kontrollü $(\mathrm{HbA} 1 \mathrm{c}<\% 6,5)$ ve kontrolsüz $(\mathrm{HbA1c}>\% 6,5)$ olarak iki grupta değerlendirmişlerdir. Bu çalışmanın sonucuna göre kök kanal tedavisi yapılan dişlerin periapikal durumları ile $\mathrm{HbA1c}$ seviyeleri arasında belirgin bir ilişki bulunmaktadır. Plazmadaki glikoz seviyelerinin değerlendirildiği bir çalışmada da benzer sonuçlar bulunmuştur. ${ }^{59}$

Segura-Egea ve ark. ${ }^{60} 2015$ yılında o döneme kadar yapılmış çalışmaları derlemişler, DM hastaları ve sağlıklı bireylerde kök kanalı tedavisi sonrası PAL varlığının karşılaştırıldığı çalışmaları bir tablo halinde özetlemişlerdir (Tablo 1). 
Tablo 1. DM hastaları ve sağlıklı bireylerde kök kanalı tedavisi sonrası PAL varlığının karşılaştırıldığı çalışmaların özeti (Segura-Egea ve ark.60)

\begin{tabular}{|c|c|c|c|}
\hline Authors (year) & $\begin{array}{c}\text { Controls } \\
\text { RFT-AP/ } \\
\text { Total RFT }(\%)\end{array}$ & $\begin{array}{c}\text { Diabetics } \\
\text { RFT-AP/ } \\
\text { Total RFT (\%) }\end{array}$ & $P$ \\
\hline Falk et al. (1989) & - & - & $>0.05$ \\
\hline $\begin{array}{l}\text { Fouad \& } \\
\text { Burleson (2003) }\end{array}$ & $224 / 467$ (48) & 63/73 (86) & $>0.05$ \\
\hline Britto et al. (2003) & $19 / 43(44)$ & $26 / 56(46)$ & $>0.05$ \\
\hline $\begin{array}{l}\text { Segura-Egea } \\
\text { et al. }(2005)\end{array}$ & $12 / 20(60)$ & $10 / 12(83)$ & $>0.05$ \\
\hline $\begin{array}{l}\text { López-López } \\
\text { et al. (2011) }\end{array}$ & $6 / 25(24)$ & $16 / 35(46)$ & $>0.05$ \\
\hline $\begin{array}{l}\text { Marotta et al. } \\
\text { (2012) }\end{array}$ & $78 / 206(38)$ & $39 / 85(46)$ & $>0.05$ \\
\hline $\begin{array}{l}\text { Ferreira et al. } \\
\text { (2014) }\end{array}$ & $3 / 23(13)$ & $10 / 31(32)$ & $>0.05$ \\
\hline Total & $343 / 784(43.8)$ & $164 / 292(56.2)$ & 0.0003 \\
\hline
\end{tabular}

Tablodaki verilere bakıldığında DM'nin kök kanalı tedavisi sorası PAL iyileşmesine olumsuz etkisinin olduğu yönünde kesin bir sonuca varılamayacağı, 2 yılın üzerindeki takip sürelerinde iyileşme intimalinin bulunabileceği ve karşılaştırmalı çalışmalar yerine epidemiyolojik çalışmaların daha doğru sonuçlar verebileceğini bildirmiş̧lerdir.

Literatür incelendiğinde, DM ve kök kanalı tedavisi sonrasında iyileşme gözlenmeyip çekim yapılan dişlerin oranları arasındaki ilişkinin değerlendirildiği epidemiyolojik çalışmalar da bulunmaktadır. ${ }^{61-64}$ Bu çalışmaların sonuçlarına göre DM'nin kök kanalı tedavisi yapılan dişlerin ağızda kalma oranının düşmesi ve çekim oranının artmasıyla direk ilişkili olduğu vurgulanmıştır.

Sonuç olarak, kontrolsüz diyabet pulpa enfeksiyonları dahil birçok ağız içi enfeksiyona yatkınlık kazandırmaktadır. Bunula birlikte, yapılan sınırlı sayıdaki epidomiyolojik çalışmalara bakıldığında DM hastalarında yeterli kontrol sağlanmazsa AP varlığı ve endodontik tedavideki başarısızlık intimalini arttırabilmektedir. Diş hekimlerinin endodontik enfeksiyonlar ve DM arasındaki muhtemel ilişkiyi göz önüne alarak teşhis ve tedavi protokollerini belirlemeleri gerektiği düşünülmektedir.

\section{KAYNAKLAR}

1. Miller WD. An instruction to the study of the bacteriopathology of the dental pulp. Dent Cosmos 1894; 36: 505-528.

2. Figdor D. Apical periodontitis: a very prevalent problem. Oral Surg Oral Med Oral Pathol Oral Radiol Endod 2002; 94: 651-652.

3. Jimenez-Pinzon A, Segura-Egea JJ, Poyato-Ferrera M, Velasco-Ortega E, Rios-Santos JV. Prevelance of apical periodontitis and frequency of root-filled teeth in an adult Spanish population. Int Endod 2004; 37: 167-173.

4. Segura-Egea JJ, Castellanos-Cosano L, Machuca G, López-López J, Martín-González J, et al. Diabetes mellitus, periapical inflammation and endodontic treatment outcome. Med Oral Patol Oral Cir Bucal 2012; 17: e356-e361.
5. Soskolne WA, Klinger A. The relationship between periodontal diseases and diabetes: an overview. Ann Periodontol 2001; 6: 91-98.

6. Katz J. Elevated blood glucose levels in patients with severe peri- odontal disease. J Clin Periodontol 2001; 28: 710-712.

7. Beck J, Garcia R, Heiss G, Vokonas PS, Offenbacher S. Periodon- tal disease and cardiovascular disease. J Periodontol 1996; 67: 1123-1137.

8. Grau AJ, Becher H, Ziegler CM, Lichy C, Buggle F, Kaiser $\mathrm{C}$, et al. Periodontal disease as a risk factor for ischemic stroke. Stroke 2004; 35: 496-501.

9. Marín C, Segura-Egea JJ, Martinez-Sahuquillo A, Bullon P. Cor-relation between infant birth weight and mother's periodontal status. J Clin Periodontol 2005; 32: 299 304.

10. Scannapieco FA, Bush RB, Paju S. Associations between peri-odontal disease and risk for nosocomial bacterial pneumonia and chronic obstructive pulmonary disease. A systematic review. Ann Periodontol 2003; 8: 54-69.

11. Bullón P, Goberna $B$, Guerrero JM, Segura JJ, Perez-Cano R, Martinez-Sahuquillo A. Serum, saliva, and gingival crevicular uid osteocalcin: their relation to periodontal status and bone mineral density in postmenopausal women. J Periodontol 2005; 76: 513-519.

12. Bender IB, Seltzer S, Freedland J. The relationship of systemic diseases to endodontic failures and treatment procedures. Oral Surg Oral Med Oral Pathol 1963; 16: $1102-1115$.

13. Joe Editorial Board. Relationship between systemic diseases and endodontics: An online study guide. J Endod 2008; 34: e195-200.

14. Lopez-Lopez J. Periapical and endodontic status of type2 diabetic patients in Catalonia, Spain: A cross-sectional study. J Endod 2011; 37: 598-610.

15. Lima SMF. Diabetes mellitus and inflammatory pulpal and periapical disease: a review. Int Endod J 2013; 46: 700-709.

16. Murray CA, Saunders WP. Root canal treatment and general health: a review of the literatüre. Int Endod $\mathrm{J}$ 2000; 33: 1-18.

17. Marotta PS. Type 2 diabetes mellitus and the prevalence of apical periodontitis and endodontic treatment in an adult Brazilian population. J Endod 2012; 38: 297-300. 18. Nagendrababu V, Segura-Egea JJ, Fouad AF, Pulikkotil SJ, Dummer PMH. Association between diabetes and the outcome of root canal treatment in adults: an umbrella review. Int Endod J 2020; 53: 455-466.

19. Segura-Egea JJ, Martín-González J, Cabanillas-Balsera D, Fouad AF, Velasco-Ortega E, López-López J. Association between diabetes and the prevalence of radiolucent periapical lesions in root-filled teeth: systematic review and meta-analysis. Clin Oral Invest 2016; 20: 1133-1141. 
20. Segura-Egea JJ, Cabanillas-Balsera D, Jiménez-Sánchez MC, Martín-González J. Endodontics and diabetes: association versus causation. Int Endod J 2019; 52: 790802.

21. Caplan DJ, Chasen JB, Krall EA, Cai J, Kang S, Garcia $\mathrm{Rl}$, et al. Lesions of endodontic origin and risk of coronary heart disease. J Dent Res 2006; 85: 996-1000.

22. Caplan DJ, Pankow JS, Cai J, Offenbacher S, Beck JD. The relationship between self-reported history of endodontic therapy and coronary heart disease in the Atherosclerosis Risk in Communities Study. J Am Dent Assoc 2009; 140: 1004-1012.

23. Mindiola MJ, Mickel AK, Sami $C$, Jones JJ, Lalumandier JA, Nelson SS. Endodontic treatment in an American Indian population: A 10-year retrospective study. J Endod. 2006; 32: 828-832.

24. Segura-Egea JJ, Jimenez-Moreno E, Calvo-Monroy C, Ríos-Santos JV, Velasco-Ortega E, Sánchez-Domínguez B, et al. Hyperten- sion and dental periapical condition. J Endod 2010; 36: 1800-1804.

25. Wang $\mathrm{CH}$, Chueh $\mathrm{LH}$, Chen SC, Feng YC, Hsiao CK, Chiang CP. Impact of diabetes mellitus, hypertension, and coronary artery disease on tooth extraction after nonsurgical endodontic treatment. J Endod 2011; 37: 1-5.

26. Segura-Egea JJ, Jiménez-Pinzón A, Ríos-Santos JV, Velasco-Or- tega $\mathrm{E}$, Cisneros-Cabello R, Poyato-Ferrera MM. High prevalence of apical periodontitis amongst smokers in a sample of Spanish adults. Int Endod J 2008; 41: 310-316.

27. Tierney LM, McPhee SJ, Papadakis MA. Current medical Diagnosis \& Treatment. International edition. New York: Lange Medical Books/McGraw-Hill. 2002; 12031215.

28. Mealey BL, Oates TW. American Academy of Periodontology. Diabetes mellitus and periodontal diseases. Review. J Periodontol 2006; 77: 1289-1303.

29. Vernillo AT. Diabetes mellitus: Relevance to dental treatment. Oral Surg Oral Med Oral Pathol Oral Radiol Endod 2001; 91: 263-270.

30. Graves DT, Liu R, Oates TW. Diabetes-enhanced inflammation and apoptosis: impact on periodontal pathosis. Review. Periodontol 2000 2007; 45: 128-137.

31. Fouad AF. Endodontic infections and systemic disease. In: Fouad AF, ed. Endodontic Microbiology. Ames, IA: Wiley-Blackwell; 2009: 320-338.

32. Siqueira JF Jr. Treatment of endodontic infections. London: Quintessence Publishing; 2011.

33. Emrich LJ, Shlossman M, Genco RJ. Periodontal disease in insulin-dependent dia- betes mellitus. J Periodontol 1991; 62: 123-130.

34. Cianciola L, Park B, Bruck E, Mosorich L, Genco RJ. Prevalence of periodontal disease in insulin-dependent diabetes mellitus. J Am Dent Assoc 1982; 104: 653-660.
35. Mealey BL, Rose LF. Diabetes mellitus and inflammatory periodontal diseases. Curr Opin Endocrinol Diabetes Obes 2008; 15: 135-141.

36. Kurtiş MB. Diyabetin periodontal dokular üzerindeki etkisi. Türkiye Klin J Periodontol-Special Topics 2015; 1: 1-6.

37. Montoya-Carralero JM, Saura-Pérez M, Canteras-Jordana M, Morata-Murcia IM. Reduction of HbA1c levels following nonsurgical treatment of periodontal disease in type 2 diabetics. Med Oral Patol Oral Cir Bucal 2010; 15: e808-e812.

38. Katz J. Elevated blood glucose levels in patients with severe periodontal disease. J Clin Periodontol 2001; 28 : 710-712.

39. Bender IB, Seltzer S, Freedland J. The relationship of systemic diseases to endodontic failures and treatment procedures. Oral Surg Oral Med Oral Pathol 1963; 16: $1102-1115$.

40. Bender IB, Bender AB. Diabetes mellitus and the dental pulp. J Endod 2003; 29: 383-289.

41. Catanzaro O, Dziubecki D, Lauria LC, Ceron CM, Rodriguez RR. Diabetes and its effects on dental pulp. J Oral Sci 2006; 48: 195-199.

42. Lima SMF, Grisi DC, Kogawa EM, Franco OL, Peixoto VC, et al. Diabetes mellitus and inflammatory pulpal and periapical disease: a review. Int Endod J 2013; 46: 700709.

43. Segura-Egea JJ, Jiménez-Pinzón A, Ríos-Santos JV, Velasco-Ortega E, Cisneros-Cabello R, et al. High prevalence of apical periodontitis amongst type 2 diabetic patients. Int Endod J 2005; 38: 564-569.

44. Marotta PS, Fontes TV, Armada L, Lima KC, Rocas IN, Siqueira JF Jr. Type 2 diabetes mellitus and the prevalence of apical periodontitis and endodontic treatment in an adult Brazilian population. J Endod 2012; 38: 297-300.

45. Lopez-Lopez J, Jane-Salas E, Estrugo-Devesa A, Velasco-Ortega E, Martin-Gonzalez J, et al. Periapical and endodontic status of type 2 diabetic patients in Catalonia, Spain: a cross-sectional study. J Endod 2011; 37: 598-601. 46. Britto LR, Katz J, Guelmann M, Heft M. Periradicular radiographic assessment in diabetic and control individuals. Oral Surg Oral Med Oral Pathol Oral Radiol Endod 2003; 96: 449-452.

47. Fouad AF, Burleson J. The effect of diabetes mellitus on endodontic treatment outcome: data from an electronic patient record. J Am Dent Assoc 2003; 134: 43-51.

48. Wu MK, Barkis D, Roris A, Wesselink PR. Does the first file to bind correspond to the diameter of the canal in the apical region? Int Endod J 2002; 35: 264-267.

49. Lele GS, Subba Reddy VV. Comparison of antibacterial efficacy of intracanal medicaments in multiple visit pulpectomies in primary molars-an in vivo study. $\mathrm{J}$ Indian Soc Pedod Prev Dent 2010; 28: 18-24. 
50. Rees TD. Periodontal management of the patient with diabetes mellitus. Periodontol 2000 2000; 23: 63-72.

51. Ship JA. Diabetes and oral health: an overview. J Am Dent Assoc 2003; 134: 4S-10S.

52. Vernillo AT. Dental considerations for the treatment of patients with diabetes mellitus. J Am Dent Assoc 2003; 134: 24S-33S.

53. Takahashi K. Microbiological, pathological, inflammatory, immunological and molecular biological aspects of periradicular disease. Int Endod J 1998; 31: 311-325.

54. Teixeira-Salum TB, Rodrigues DB, Gervasio AM, Souza CJ, Rodrigues V Jr, et al. Distinct Th1, Th2 and Treg cytokines balance in chronic periapical granulomas and radicular cysts. Journal of Oral Pathology and Medicine 2010; 39: 250-256.

55. Fukada SY, Silva TA, Garlet GP, Rosa AL, Silva JS, Cunha FQ. Factors involved in the T helper type 1 and type 2 cell commitment and osteoclast regulation in inflammatory apical diseases. Oral Microbiol Immunol 2009; 24: 25-31.

56. Chang PC, Lim LP. Interrelationships of periodontitis and diabetes: A review of the current literature. J Dent Sci 2012; 7: 272-282.

57. Vestergaard P. Discrepancies in bone mineral density and fracture risk in patients with type 1 and type 2 diabetes a meta-analysis. Osteoporos Int 2007; 18: 427-444.

58. Sánchez-Domínguez B, López-López J, Jané-Salas E, Castellanos-Cosano L, Velasco-Ortega E, Segura-Egea JJ. Glycated hemoglobin levels and prevalence of apical periodontitis in type 2 diabetic patients. J Endod 2015; 41: 601-606.

59. Cheraskin E, Ringsdorf WM Jr. The biology of the endodontic patient. 3. Variability in periapical healing and blood glucose. J Oral Med 1968; 23: 87-90.

60. Segura-Egea JJ, Martín-González J, Castellanos-Cosano L. Endodontic medicine: connections between apical periodontitis and systemic diseases. Int Endod J 2015; 48: 933-951.

61. Mindiola MJ, Mickel AK, Sami C, Jones JJ, Lalumandier JA, Nelson SS. Endodontic treatment in an American Indian population: a 10-year retrospective study. J Endod 2006; 32: 828-832.

62. Doyle SL, Hodges JS, Pesun IJ, Baisden MK, Bowles WR. Factors affecting outcomes for single-tooth implants and endodontic restorations. J Endod 2007; 33: 399-402. 63. Wang $\mathrm{CH}$, Chueh $\mathrm{LH}$, Chen SC, Feng YC, Hsiao CK, Chiang CP. Impact of diabetes mellitus, hypertension, and coronary artery disease on tooth extraction after nonsurgical endodontic treatment. J Endod 2011; 37: 1-5.

64. Ng YL, Mann V, Gulabivala K. A prospective study of the factors affecting outcomes of non-surgical root canal treatment: part 2: tooth survival. Int Endod J 2011; 44: 610-625. 